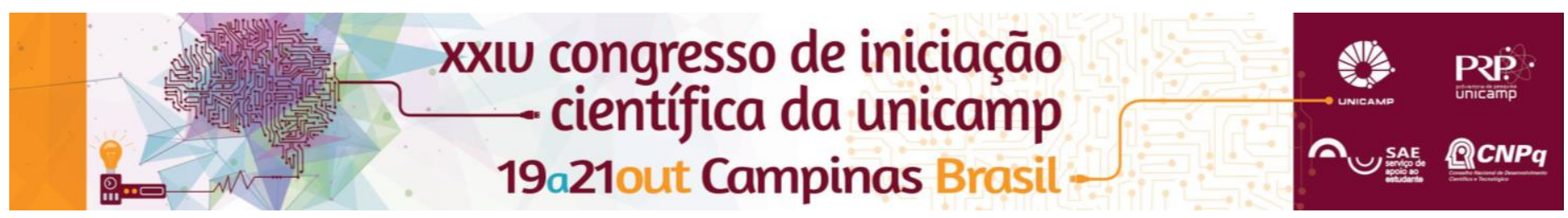

\title{
Associação entre a autoeficácia materna e tipo de aleitamento na alta hospitalar.
}

\author{
Gabriela de Godoy Jeronimo (IC)*, Jucilene Casati Lodi (PG), Rosana de Fatima Possobon (PQ).
}

\section{Resumo}

Este estudo investigou a associação entre autoeficácia materna, variáveis socioeconômicas, demográficas e obstétricas e o aleitamento materno exclusivo no momento da alta hospitalar. Participaram 210 mães usuárias das Unidades de Saúde da Família no município de Piracicaba-SP, que responderam o instrumento de autoeficácia geral e na amamentação e sobre condições socieconômicas e demográficas. As variáveis idade paterna, renda, aceitação da gestação pelo pai, não ocorrência de complicações maternas, vontade de amamentar e alto nível de autoeficácia geral mostraram associação com o aleitamento materno exclusivo na alta hospitalar.

\section{Palavras-chave:}

Aleitamento Materno Exclusivo, autoeficácia na amamentação, desmame precoce.

\section{Introdução}

Os benefícios do aleitamento materno para a díade mãelactente são amplamente conhecidos e divulgados, entretanto, a adesão está abaixo do que é recomendado pela Organização Mundial de Saúde ${ }^{1,2}$. A falta de confiança materna diante da sua capacidade em amamentar, estudada pelo constructo da autoeficácia ${ }^{3}$, pode estar associada à interrupção total ou à complementação do aleitamento materno. Este estudo investigou a associação entre autoeficácia da gestante/puérpera e a prática do aleitamento materno exclusivo no momento da alta hospitalar. As mães foram abordadas em dois momentos: no último trimestre da gestação, quando responderam questões socioeconômicas e demográficas e os Instrumentos de Autoeficácia Geral Percebida e Autoeficácia na Amamentação (BSES); e na primeira semana de vida do bebê, para verificação da prática do aleitamento no momento da alta hospitalar.

\section{Resultados e Discussão}

Participaram deste estudo 210 gestantes/puérperas assistidas pelas Unidades de Saúde da Família (USF) do município de Piracicaba-SP. Renda mensal familiar superior a 5 salários mínimos vigentes na época da coleta dos dados, nascimento a termo, ausência de complicações maternas, ter vontade de amamentar e alto nível de autoeficácia geral percebida estiveram associadas coma prática do aleitamento materno exclusivo no momento da alta hospitalar.

\footnotetext{
1. Brasil. Ministério da Saúde. Atenção ao Pré-Natal de Baixo Risco. Departamento da Atenção Básica. Brasília: Editora do Ministério da Saúde, 2012.

2. Oriá MOB, Ximenes LB. Tradução e adaptação cultural da Breastfeeding Self-Efficacy Scale para o português. Acta Paul Enferm. 2010; 23 (2):230-38.

3. Dennis CL, Faux S. Development and psychometric testing of the Breastfeeding Self-Efficacy Scale. Rev. Nurs Health. 1999; 22(5):339409
}

Tabela 1: Associação entre variáveis socioeconômicas, demográficas, obstétricas e níveis de autoeficácia e o aleitamento materno exclusivo na alta hospitalar. Piracicaba, SP, 2015.

\begin{tabular}{|c|c|c|c|c|c|c|c|}
\hline \multirow[t]{2}{*}{ Variáveis } & \multirow[t]{2}{*}{ Categorias } & \multirow[t]{2}{*}{$\begin{array}{l}\text { Amostra } \\
\mathrm{N}=210\end{array}$} & \multicolumn{2}{|c|}{$\begin{array}{c}\text { Aleitamento materno } \\
\text { exclusivo (alta hospitalar) }\end{array}$} & \multirow[t]{2}{*}{ OR } & \multirow[t]{2}{*}{ IC $(95 \%)$} & \multirow[t]{2}{*}{ p-valor } \\
\hline & & & Sim & Năo & & & \\
\hline \multirow[t]{2}{*}{ Idade materna } & $\leq 24$ & $105(50 \%)$ & $80(76,2 \%)$ & $25(23,8 \%)$ & 1,53 & $0,84-2,81$ & 0,2194 \\
\hline & $>24$ & $105(50 \%)$ & $71(67,6 \%)$ & $34(32,4 \%)$ & 1,00 & & \\
\hline \multirow[t]{2}{*}{ Idade paterna } & $\leq 29$ & $109(51,9 \%)$ & $85(78 \%)$ & $24(22 \%)$ & 1,88 & $1,02-3,46$ & 0,0599 \\
\hline & $>29$ & $101(48,1 \%)$ & $66(65,3 \%)$ & $35(34,7 \%)$ & 1,00 & & \\
\hline \multirow[t]{2}{*}{ Renda } & $\leq 5$ & $123(58,6 \%)$ & $85(69,1 \%)$ & $38(30,9 \%)$ & 1,00 & & \\
\hline & $>5$ & $87(41,4 \%)$ & $66(75,9 \%)$ & $21(24,1 \%)$ & 1,41 & $0,75-2,62$ & 0,03590 \\
\hline \multirow[t]{2}{*}{ Escolaridade materna } & $\leq 8$ & $174(82,9 \%)$ & $123(70,7 \%)$ & $51(29,3 \%)$ & 1,00 & & \\
\hline & $>8$ & $36(17,1 \%)$ & $28(77,8 \%)$ & $08(22,2 \%)$ & 1,45 & $0,62-3,40$ & 0,5108 \\
\hline \multirow[t]{2}{*}{ Paridade } & Primípara & $104(49,5 \%)$ & $80(76,9 \%)$ & $24(23,1 \%)$ & 1,64 & $0,89-3,02$ & 0,1473 \\
\hline & Multipara & $106(50,5 \%)$ & $71(67 \%)$ & $35(33 \%)$ & 1,00 & & \\
\hline \multirow{2}{*}{$\begin{array}{l}\text { Qualidade da } \\
\text { experiência }\end{array}$} & Boa & $62(30,5 \%)$ & $39(62,9 \%)$ & $23(37,1 \%)$ & 1,00 & & \\
\hline & Ruim & $42(20 \%)$ & $31(73,8 \%)$ & $11(26,2 \%)$ & 1,66 & $0,70-3,93$ & 0,3419 \\
\hline \multirow{2}{*}{$\begin{array}{l}\text { Presença do } \\
\text { companheiro }\end{array}$} & Sim & $137(65,2 \% 0$ & $112(81,8 \%)$ & $25(18,3 \%)$ & 1,69 & $0,86-3,31$ & 0,1732 \\
\hline & Nã̃o & $73(34,8 \%)$ & $53(72,6 \%)$ & $20(27,4 \%)$ & 1,00 & & \\
\hline \multirow[t]{2}{*}{ Aceitação pelo pai } & Sim & $187(89 \%)$ & $140(74,9 \%)$ & $47(25,1 \%)$ & 3,25 & $1,34-7,86$ & 0,0133 \\
\hline & Nåo & $23(11 \%)$ & $11(47,8 \%)$ & $12(52,2 \%)$ & 1,00 & & \\
\hline \multirow[t]{2}{*}{ Tipo de Parto } & Normal & $109(52 \%)$ & $82(75,2 \%)$ & $27(24,8 \%)$ & 1,41 & $0,77-2,58$ & 0,3371 \\
\hline & Cesárea & $101(48 \%)$ & $69(68,3 \%)$ & $32(31,7 \%)$ & 1,00 & & \\
\hline \multirow[t]{2}{*}{ Tempo Gestacional } & Termo & $171(81,4 \%)$ & $131(76,6 \%)$ & $40(23,4 \%)$ & 3,11 & $1,51-6,40$ & 0,0029 \\
\hline & Pré-Termo & $39(18,6 \%)$ & $20(51,3 \%)^{\circ}$ & $19(48,7 \%)$ & 1,00 & & \\
\hline \multirow{6}{*}{$\begin{array}{c}\text { Complicações } \\
\text { Maternas } \\
\text { Vontade de } \\
\text { Amamentar } \\
\text { Autoeficácia GERAL }\end{array}$} & Sim & $47(22,4 \%)$ & $23(48,9 \%)$ & $24(51,1 \%)$ & 1,00 & & \\
\hline & Nã̃o & $163(77,6 \%)$ & $128(78,5 \%)$ & $35(21,5 \%)$ & 3,82 & $1,93-7,56$ & 0,0001 \\
\hline & Sim & $200(95,2 \%)$ & $151(75,5 \%)$ & $49(24,5 \%)$ & 27,34 & $3,43-224,46$ & $<0,0001$ \\
\hline & Nảo & $10(4,8 \%)$ & $01(10 \%)$ & $09(90 \%)$ & 1,00 & & \\
\hline & Baixa & $14(6,7 \%)$ & $06(42,9 \%)$ & $08(57,1 \%)$ & 1,00 & & \\
\hline & Alta & $196(93,3 \%)$ & $145(74 \%)$ & $51(26 \%)$ & 3,79 & $1,25-11,45$ & 0,0281 \\
\hline \multirow{3}{*}{$\begin{array}{l}\text { Autoeficácia na } \\
\text { Amamentação }\end{array}$} & Baixa & $85(40,5 \%)$ & $68(80 \%)$ & $17(20 \%)$ & 1,17 & $0,55-2,50$ & 0,8276 \\
\hline & Média & $75(35,7 \%)$ & $58(77,3 \%)$ & $17(22,7 \%)$ & 1,00 & & \\
\hline & Alta & $50(23,8 \%)$ & $39(78 \%)$ & $11(22 \%)$ & 1,04 & $0,44-2,46$ & 0,8955 \\
\hline
\end{tabular}

\section{Conclusão}

O nível de Autoeficácia Geral Percebida mostrou ser uma variável preditora da prática de aleitamento materno exclusivo no momento da alta hospitalar, sendo que o instrumento é de fácil aplicação o que estimula o seu uso para identificação de mães com maior risco de desmamar precocemente.

\section{Agradecimentos}

À PIBIC-CNPq pela concessão da bolsa de Iniciação Científica. 